Informal Logic

X.3, Fall 1988

\title{
Reportage as Compound Suggestion
}

\author{
JOHN D. MAY
}

\begin{abstract}
Journalistic narrative prose is rich in suggestion. By voicing a single narrative ("X happened") statement in a supposedly non-fiction context, sender invites receiver to impute intelligibility, ascertainability, feasibility, topicality and speaker sincerity, as well as veracity, to the terms of an account. Conversely, when a narrative statement passes through a 'news-giving' medium, receivers are deterred from appraising those invited inferences. Similar inducements come from pseudonarrative statements. Meanwhile, some narratives convey other suggestions. Without being explicit they invite extra-logical inferences about event locations, agent numbers, chronologies, relative importance, and determinants, as well as current practicabilities. Awareness of such suggestions is the first step toward distinguishing between prudent and foolhardy inferences.
\end{abstract}

The thoughts which occupy human minds are shaped by external events. Sights and sounds impinge on our senses, which send signals to our brains, which interpret the signals and decide what to do. Among those formative signals are words. Of the many stimuli which shape human thought, a substantial portion, especially in modern societies, are verbal-words spoken and written by other people.

Relations between verbal cue and mental response seem to be irregular. A given message triggers various thoughts in various rauditors (readers and/or listeners). Rauditors respond not only to the terms of a message but also to its source, tone, context, and medium of transmission. Rauditors differ, meanwhile, in attitudes, circumstances, moods, receptors, linguistic training and felt needs. They differ accordingly in how they construe a given message.
But relations between messages and mental responses are not althogether irregular. Consider, for instance, the utterance "Hello; isn't it a nice day." Upon hearing those words, from just about anybody, on just about any occasion, almost anybody who understands English would feel prompted to adopt these ideas: 'I understand that utterance; I ought to think now about the state of the weather; the speaker believes what she has just said; it is a nice day; I ought to say so.'

On various occasions various people would start additional trains of thought, such as "Why did she say that to me?" They also would differ in decisions about whether to adopt the ideas suggested by the instigating utterance. They still would be showing some uniformity in responses to a verbal stimulus.

Investigators have long sought to map such uniformities. Aristotle's venerable catalogue of rhetorical devices represents a series of observations not just about recurring patterns of speech but about recurring mental responses as well. Certain modes of argument, Aristotle taught, persistently entice us to adopt certain ideas-including ideas which, in relation to the triggering statements, are deficient in logical validity.

Modern students of communication have persisted with efforts to identify extralogical, non-entailed suggestions which get conveyed by recurring patterns of speech. Relevant observations made by these pragmatically-orientated linguists have been made under a multitude of labels: "implicit assumption" and "implicit conclusion" (Beardsley, 1950, Ch. 2): "contextual im- 
plication" (Nowell-Smith, 1954, ch. 6); "presupposition" (Stalnaker, 1974; Kempson, 1975); "pragmatic presupposition", (Stalnaker, 1975); "informal inference" ("use of one sentence to convey the meaning of another"; Gordon \& Lakoff, 1971); "pragmatic inference" (ibid.); "conventional implicature" and "conversational implicature" (Grice, 1973); semantic "expectation" (Leech, 1974, Ch. 14; Vestergaard \& Schroder, 1985); "entailment-incontext" (G. Lakoff, 1977); variation in "underlying representation" (Clark \& Clark, 1977, ch. 1); "implicature" ("process whereby meanings are read into sentences"; Stalnaker, 1977, via Grice); "conversational implication" (Fogelin, 1978); "hermeneutic meaning" (Williamson, 1978, p. 86); "communicative force" (Leech, 1980); "pragmatic force" (ibid.); " indirect meaning" (Leech, 1980; Geis, 1982); " pragmatic inference"' (Geis, 1980); "pragmatic implication"' (Pateman, 1983); and "implicit import" (Blakemore, 1987, p. 69).

Many of those labels are misleading. They conjure up images of 'meanings' (literal and non-literal, logical and extra-logical) which repose in statements, to be seen or not as the case may be. Such images divert attention from the fact that words do not have intrinsic meanings, but only have uses.

A more suitable name for the extralogical suggestions or pragmatic meanings which are prompted regularly by patterns of speech would be invited inference. This label was used back in 1971 by Michael Geis and Arnold Zwicky. In a short paper, Geis and Zwicky publicized three patterns of invited inference:

- "Conditional Perfection". Saying "If you mow the lawn, I'll pay you five dollars" invites the addressee to infer that if he does not mow the lawn, the speaker will not pay him five dollars. More generally, saying "If $A$, then $B$ " invites the inference that if $A$ does not occur, $B$ will not occur.

- "Biconditional Perfection". Statements of the form "If $A$ or $B$, then $C$ "' invite the inference that if neither antecedent occurs, then the consequent will not occur (or be true).

-Succession as Causation. Saying "After a heavy meal, he slept soundly" invites the inference that the diner's heavy meal caused his sound sleep. This illustrates the general situation whereby chronological statements (" $A$, then $B$ ") invite causal inferences (" $B$ happened because $A$ happened").

The latter case brings to mind Aristotle's warning that antecedence does not suffice to establish a causal link between events. Perhaps Aristotle emphasized that point because many speakers in his time induced their auditors to make that 'hasty' inferential leap, which has come down to us in the form of the latinized expression post hoc, ergo propter hoc. Perhaps Aristotle also deemed it more important to emphasize the deductive invalidity of the invited inference than to assess its prudential cogency or its probability of being true. At any rate, the point made by Geis and Zwicky is that in ordinary discourse a person who voices some variation of " $A$, then $B$ "' encourages a causal inference (' $A$ caused $B$ ') without endorsing it.

In this paper I undertake to enlarge the recorded inventory of invited inferences. At the same time I concentrate on patterns of invited inference that occur within a particular mode of discourse, namely, reportage or journalistic narration.

Narrative discourse differs as verbal activity from promising, explaining, exclaiming, prescribing, evaluating, defining, prognosticating, and giving ongoing descriptions. To engage in narration is to voice claims about what has happened, as distinct from claims about the why of things or claims about what is happening, could happen, might happen, or ought to happen. Narrating is the syntactic vehicle, then, of story-tellers: novelists, fabulists, raconteurs, historians, and news reporters.

'Journalistic narration' is my label for discourse which is narrative in form and is delivered in the guise (explicitly or implicit- 
ly) of recounting true events. Such discourse includes what personal informants say when they give putatively factual reports as well as what is billed on radio and television as "newscasts" and what appears in the "news" columns of the daily Press.

As is demonstrated in the following pages, journalistic narratives are rich in suggestion-and sometimes are insidiously suggestive. Just as "Hello; isn't it a nice day" prompts several lines of thought, so does "Three persons died in a highway collision this morning." A single bit of putative reportage (" $X$ happened") invites not just one inference (such as ' $X$ did indeed happen') but several. And while every message is unique (in content, context and recipients), there are underlying regularities. Some types of inference are invited by virtually any narrative sentence delivered in any reportorial context. Certain sub-types of narrative sentences, moreover, convey additional types of suggestions.

\section{General Suggestions}

Just about any bit of journalistic narrative conveys, to just about any rauditor in any setting, six kinds of suggestions. These are that the nominated event is abnormally salient or noteworthy, that the narrator's account is true, that the narration's terms are meaningful, that the event(s) recounted could have occurred, that the narrator could have ascertained what (s)he recounts, and that the narrator believes all of the foregoing.

Salience. Every narrative statement is an act of selection. The narrator chooses to recount one past event at the expense (momentarily at any rate) of other events. ${ }^{1}$ As processors of messages that come our way, we sense this selectivity. And in consequence of that awareness, we experience journalistic narratives as invitations to ascribe special weight to cited events relative to other events (see Blakemore,
1987, esp. Ch. 2). Narratives thus operate as suggestions not only about what has occurred but also about what has not occurred.

Salience Nudges can be quantitative and qualitative in character. The quantitative hint has been illustrated by Stephen Levinson $(1983, p .136)$ in the context of a dialogue. If Jones is asked "How did Harry go in court yesterday?" and he replies "Harry got a fine," Jones conveys the suggestion that no bigger penalty was imposed. By the same token, a narrator who says "Harry hit Mary" conveys the suggestions, that Harry did indeed hit Mary and that he did not also stab, shoot or kill Mary and that he did not hit Sherri and Barry as well as Mary.

These cases illustrate the point that statements of the form " $X$ happened" invite the inference that no other X-type event occurred that was greater in magnitude.

Coinciding with this quantitative nudge concerning salience is a qualitative nudge. A putative informant who says " $X$ happened" invites rauditors to infer not only that event $X$ did indeed occur but also that $X$ 's occurrence out-ranks other events (or other aspects of the cited event) in importance.

Qualitative Salience Nudges work in bunches; and they work cumulatively. Today's newspaper says, in effect, "The events reported here out-rank all others in importance." A year's issues say, in effect, "The types of events persistently reported here out-rank all others in importance."

This aspect of news-giving has been the foundation for complaints about the mainstream news media. According to various critics, the media give disproportionate attention to bad news (conflicts, disasters), to events in modern as distinct from Third World states, to incument authority-figures, to headline-hunting dissidents, to conflicts other than class conflicts, and/or to trivia.

Equally controversial can be qualitative Salience Nudges imparted by narrators' choices among aspects of events given coverage. Illustrating the matter is the 


\section{following sentence:}

The Libocrat Party scored an 8 per cent gain in yesterday's national elections.

Those words represent the kind of opening statement that gets transmitted through the mass media soon after popular elections have been held on the same date in many districts. The sentence reads like straight reportage (a summing up of compound results), but as real-world discourse it exemplifies a bold qualitative judgment.

To appreciate that point we must first take due note of the fact that people, not organizations or collectivities, stand for elective office. The candidates often are affiliated with parties, but they also have other affiliations and other traits. From this it follows that the quoted sentence, taken at face value, is a piece of fiction. The sentence "reports" the political fortunes of a contestant who, or which, did not exist as a contestant.

But another assessment is possible. This one is based on construing the quoted sentence as a bit of figurative description blended with interpretation.

According to this construction, the quoted sentence really is a claim-using anthropomorphic prose, or Personation-that candidates affiliated with the Libocrat Party increased their collective share of parliamentary seats by 8 per cent. In addition, the quoted sentence really is a claim that the most noteworthy, or qualitatively salient, thing about the many outcomes of yesterday's many electoral contestants was this change in proportions of seats held by people affiliated with various partisan organizations.

Now in mainstream political journalism, as it happens, this Salience Nudgerecounting election results with paramount attention being given to parties - happens to be conventional. Another chronicler could recount the result(s) of yesterday's national elections in terms of changes in the proportions of seats occupied by greybeards, proletarians, secular humanists, southerners, Masons, left-handers or women. By comparison with our cited passage, those choices of Salience Nudge would be less conventional-would appear to be arbitrary and tendentious-but they would be no less, or more, reportorial.

Although the conventional way of reporting election results also is arbitrary and tendentious, it is not necessarily the expression of a worked-out ideology. Mainstream journalists do not necessarily subscribe to the judgment they encourage, namely, that the most important results of popular elections are changes in the fortunes of "the parties." The journalists may simply be aping an established practice. And that practice may have come about as a result of trying to find some way of generalizing, in an apparently impartial way, about the results of many simultaneously-held elections.

Veracity. The most direct suggestion conveyed by journalistic narratives, in contrast to fictive narratives, is the suggestion that the nominated event did indeed take place. Journalistic narratives invite us to make inferential leaps in which an oral event (Bloggs saying " $X$ happened" in a newsgiving context) is taken as evidence that another event $(X)$ took place.

Journalistic narratives differ not only in the contents of their suggestions about the identity of what has happened, but also in strength or richness of claims. Some reports are stronger substantively than others without being more verbose. They incite richer, more complete, impressions of past occurrences. Such variations may stem from choices of verbs. "Bev believed that Paul is a poof" conveys a suggestion about Bev's state of mind; but "Bev realized that Paul is a poof" invites that same inference plus the inference that Bev's belief corresponds to reality (see Bach \& Harnish, 1979, Ch. 8). ${ }^{2}$ Similarly, "Walt walked to Wagga Wagga" is a stronger, more informative statement than "Walt went to Wagga Wagga." Again, while "Sam said..." invites only the categorical inference that Sam 
performed a verbal sort of action, "Carl confessed..." invites the additional, subcategorical inference that Carl performed a confessional type of verbal action.

The effect on rauditors can be substantial. We are not left altogether free to decide, on the basis of its reported content, what kind of statement Carl made. We are encouraged to make a categorical judgment. ${ }^{3}$ And we are deterred from assessing that judgment.

Some of these categorical suggestions point us in odd directions. Consider this bit of journalism:

A man behind a proposed $\$ 35$ million housing development...was described in State Parliament yesterday as a despicable undesirable who would be facing prosecution.

Here we are invited to believe not only that an MP called somebody a despicable undesirable but also that in doing so he was engaging in description, not characterization or denunciation. Similarly:

Political writer John Stubbs was the first journalist to report Sir Joh Bjelke-Petersen`s

fall from power was imminent.

This bit of journalism invites us to confound prognosticative verbiage with reportage.

Intelligibility. Also encouraged by the voicing of some variant of the utterance type " $X$ happened" is an inference concerning clarity. The invited inference is that the terms of what was said are readily comprehensible. To say " $X$ happened" thus is to encourage the belief that for linguistically normal people one's statement is intelligible.

This kind of nudge, like other invited inferences, can be disarming. It invites a rauditor who feels baffled by what has been narrated (by the sense of an account, as distinct from its truth or its implications) to feel eccentric and/or deficient as well. It deters us from imputing incoherence to incoming texts.
The Intelligibility Nudge is only mildly disarming when authors use exotic words, as in a sentence such as "A drosophila marsitans bit rich Aunt Betsy." There the invited inference is that most rauditors know what a drosophila marsitans is-and thus that the ignorant ones have reason to feel inadequate. But the presence of a comprehension problem is readily apparent. And so is the solution: looking in a dictionary, which discloses that the alleged Betsy-biter was a fly.

More disarming are cases wherein speakers resort without warning to figurative expressions. Such cases pervade the news media. Scarcely a day passes without deadpan accounts of words uttered by buildings (the White House, Whitehall, the Kremlin, the Quai d'Orsay), by cities (Beijing, Moscow), by companies ("Chrysler announced..."), by circles ("scientific circles said..."), and by other putatively vociferating entities. Although we understand the terms used (and thus do not think of resorting to dictionaries), we are hard pressed to grasp the sense of what is being expressed. And yet we feel that there must be a sense, and a common sense at that, else the expression would not be used so persistently. This feeling is fortified by the omission of explicit translations of figurative expressions. The resulting insinuation is that translation would be superfluous.

Relief sometimes is provided by additional bits of text. Thus, if a sentence ostensibly recounting words uttered by the White House is followed by sentences ostensibly recounting words uttered by the President's press secretary, an experienced news consumer may guess that "the White House said...." is journalistic short-hand for "the President's press secretary, acting in his official capacity, said...."

In other cases, contextual clues furnish only an illusion of intelligibility. This occurs with particular frequency in putative reports about movements-forward, backward, left-ward (or Left-ward) and 
right-(Right-)ward-accomplished by countries, governments, political parties and other surprisingly mobile entities. Past experience and contextual cues may prompt us to construe such chronicles as figurative narrations. But what are their literal equivalents? When explicit translations are not provided, and when the untranslated figures of speech occur frequently in political journalism, rauditors are induced to suppose that the literal sense of such expressions is clear to everybody else if not to self

Contextual clues may compound the illusion. Thus, a putative report saying "Canada tilted to the Right yesterday" could be followed by a statement that "the New Democratic Party suffered a net loss of six parliamentary seats" in national elections. This usage invites readers to construe "Right-ward tilt" as "loss for New Democrats." But the journalist could have said simply that the New Democrats lost six seats. By NOT doing that straightforward thing she suggests that "loss for New Democrats" and "Right-ward tilt"' are NOT equivalents; they are related in some other way. The non-figurative sense of "tilted to the Right' has not been clarified. And no dictionary entry sheds light on the subject. Those daily reports of backward, sinister and dexter movements around the world are so much bafflegab. (See J. May, 1983).

Feasibility. Another suggestion conveyed by statements of the form " $X$ happened" is that the named event belongs to a class of things which can happen. ${ }^{4}$ This suggestion is categorical. By saying "The Chilean capital city of Santiago was rocked by an earthquake yesterday' - and speaking in a putative news-giving context-I invite the inferences that earthquakes can happen and can occur in Chile. Similar suggestions of categorical feasibility would be conveyed by saying -in a putative news-giving context-"An earthquake rocked heaven yesterday." Formally narrative remarks delivered in news-giving contexts deter critical thought about the truth-value of their claims about what has taken place.

When claims which lack truth value are delivered in the guise of journalistic narration, this influence is insidious.

Such deceptions can readily occur. The narrative mode of expression can serve as the vehicle for an assortment of nonexpository assertions. By way of illustration let us consider three sentences:

Belle pinched Bill's bottom yesterday.

Belle committed a misdemeanor yesterday.

Belle did a naughty thing yesterday.

Each of these sentences is narrative in form, but only the first two are narrative in content as well. The first two give putative information about a past event, whereas the third only nominates (expresses and/or recommends) an attitude toward an event which has not been identified. The third sentence is an evaluative, not an expository, statement, and thus cannot be either true or false. This difference can be obscured, however, by the formal similarity of the sentences, and it can be obscured further by similarity of medium or context. If it were delivered in the guise of "news," the third sentence could be perceived as news-as a truth-valuable version of what has taken place, rather than as moral judgment.

Fortifying that misperception would be the fact that our third sentence's key valuating term appears as an adjective. This too can induce a misperception about the character of what has been said. Many adjectives are descriptive rather than evaluative. Such is the case, for example, with "Belle did an illegal thing'" as contrasted with "Belle did a naughty thing." The syntactic similarity between these sentences nudges us in the direction of imputing similarity of 'status', i.e., of truthvalue. In the words of Schmidt \& Kress (1985, p. 289), "'a prenominal modifier seems to describe an integral property of the noun, giving the impression of classification as opposed to evaluation." 
"This fact can be exploited": "by placing attributive adjectives in prenominal position, as in 'a harmless lie'," speakers give moral judgments the appearance of objective descriptions.

Moral judgments are not the only kinds of non-descriptive remarks which can come across, by means of context and form, as truth-valuable narratives. In the mainstream mass media, other kinds of pseudonarratives are more common. Here are some noteworthy cases:

Another victory for the parish priests.

This sentence was delivered in the course of a "report" on the Australian version of Sixty Minutes (a television public-affairs program). Preceding it and following it were plainly expository remarks about the outcome of popular voting in Ireland on proposals to liberalize laws concerning divorce. Those contextual factors work to fortify the suggestion that the quoted sentence, like its predecessors and successors, is straight reportage. To put the matter another way, the contextual factors collaborate so as to deter auditors from noticing that the quoted sentence is not reportage-not narration, not exposition-but instead is a bit of gratuitous, politically loaded explanation. The invited inference-that the voters did what they did because they were brainwashed and/or intimidated by their parish priests-becomes all the more credible by appearing to be something else, namely, straightforward description.

The announcement [by Gorbachev] was a devastating blow [to Reagan], all but ending his last best hope for...

Viewed in isolation, this sentence can be classified readily not as exposition or narration, nor as editorializing, but as situational appreciation. It does not describe or evaluate events. It expresses an estimate of the implications-the 'meaning'; the likely future consequences - of recent events. But the sentence appeared in TIME, "the weekly newsmagazine" (2 Nov. 1987), and it was surrounded by other sentences which were narrative in form and content. In such a setting, such a pseudo-narrative invites the inference that its terms can be true.

More insidious still are sentences whose terms closely resemble the language of true narration.

The Liberal Party launched itself on the path of political independence yesterday.

Queensland's government came closer to collapse yesterday...

These sentences appeared on the first page of a broadsheet newspaper. Each opened an article which was not tagged "Comment" or "Analysis" and thus was billed tacitly as straight reportage. But the events ostensibly recounted by these sentences could not have occurred. "The Liberal Party" is not the name of any sentient, willful organism which is capable of launching itself. Governments are not organisms or structures which can remain upright or can collapse.

If we construe the sentences as figurative expressions, however, we can see them not as metaphorical descriptions of events but as situational appreciations. Their authors are inviting us to regard certain events (to be identified later?) as moves by a "party" toward "political independence" and by a government toward its own termination.

Here are some additional bits of journalism which convey a Feasibility Nudge:

"The stock market pushed ahead, struggling to surpass its previous high for the year.",

Between rounds, ecology voters were ardently wooed by both right and left.... But the decentralized ecology movement [in West Germany] stubbornly refused to endorse any of the major candidates in the second round, urging its supporters instead to make their own choices.

Sydney University in particular has in the past thought of itself as a preferred institution....

Federal Government interest rates are expected to fall.... 
The whole of Australia held its breath yesterday as....

Now was the time for optimism..., the Treasurer said last night.

Taken at face value, these bits of putative reportage invite rauditors to believe that a stock market can push and struggle, that a "right" and a "left" can woo, that a "movement" can engage in acquiescing or refusing, that a Sydney university can think, that expectations can exist independently of expecters, that Australia is endowed with lungs, and that Federal Treasurers can talk. Those suggestions about what can be true, moreover, are reinforced by the medium of transmission: each was delivered in the contextual guise of news-giving.

Of the several suggestions, however, only the latter comports with conventional notions of what can be. It alone passes the Possibility Test-if we think to apply that test. It alone becomes eligible for application of the Probability Test, in which one makes an estimate of the chance that a Treasurer said "Now was."

As for the other statements, although they do not pass the Possibility Test (if we think to apply it) they still may provide information. Using relevant experience as well as clues provided in other parts of a given text, a rauditor may be able to 'translate' such expressions into truthvaluable reports. This effort requires, first of all, recognition of the need. The rauditor must recognise that statements phrased in narrative language, and delivered in the guise of 'straight news,' are not what they seem.

Ascertainability. By making a statement of the form " $X$ happened" I augment the Feasibility Nudge (" $X$ could have happened") with a suggestion about what can (and cannot) be learned. Tacitly I nominate " $X$ " as an event whose occurrence is detectable by contemporary humans. Every putative report thus is a mini-essay in epistemology. Various narratives make various epistem- ological claims.

Many newspaper stories open with sentences containing an attribution clause. And most attribution clauses contain the phrase "said yesterday." This phrase signals that the journalist is being modest epistemologically: she is only claiming to have ascertained what words a news source uttered. This kind of thing is easy enough technically (hard as it may be to get some statements out of some sources). It is much easier than ascertaining whether a source believes what he says or whether a source's version of what has happened is true.

Some putative news stories, however, are more audacious epistemologically:

Soviet troops have shelled a mosque in a small village northwest of Kabul, killing more than 55 people.

Two Soviet-built fighters of the Libyan Air Force were shot down today in the Mediterranean by US fighters ... after they had made an unprovoked attack on the American planes.

More than 90 per cent of the electorate voted in Vietnam's first general election in 20 years and there were no incidents in the 12-hour polling period which ended with jubilant youths singing in Saigon streets.

These passages invite rauditors to credit the authors with observational feats which while being possible technically must have been exceedingly difficult circumstantially. The authors voice direct accounts of events occurring in spots which are not readily accessible to journalistic scrutiny. They do not make the relatively modest claims of having succeeded in recording words delivered by sources such as Tass employees, a Pentagon publicist, or a Radio Hanoi broadcaster.

\footnotetext{
...the coalition looks doomed anyway. This weekend's exercises are aimed at persuading the voter that the blame is on the other side. The Nationals are still hoping that the Liberals will get cold feet. But Liberal Party headquarters believe that they're going to improve their [electoral] standing.
}

This passage invites belief that the 
speaker ascertained the aims of exercises, the hopes of "the Nationals," and at least one belief of a headquarters. Such tacit claims require us to believe that some people on some occasions can perform such feats of detection.

Walter Mondale released a 25-year old letter from Ronald Reagan to Richard Nixon... It was a deliberate attempt by $\mathrm{Mr}$. Mondale to stop Mr. Reagan from persistently quoting from former Democratic leaders....

National Party officials in Queensland want to create a chair of 'free enterprise' at a State university to counter....

Painless Budget Framed with Next Year's Election in Mind.

These statements-all delivered in the guise of 'straight news'-invite us to credit their authors with mind-reading powers.

Terry White was sacked from the Cabinet "because his conscience vote clashed with his leader's view of the tradition of Cabinet solidarity."

Terry White was sacked for "crossing the floor to support a call for a public accounts committee."

White was sacked "for supporting his party's public accounts committee policy."

These sentences-in-context also invite us to credit their authors with mind-reading powers. In purporting to disclose why a particular deed was performed, the authors claim tacitly to be able to detect the motivational well-springs of human actions. They are being more presumptuous epistemologically than journalists who claim only to report what rationales are given by decisionmakers. (The cited passages, to repeat, were delivered in the guise of straight news. They were not billed as guesses about motivation or causation).

Over the last four weeks in Brisbane, the faith of former beautician Jan Painter has cured one case of cancer, one of emphysema, kidney stones, and 'a heap of alcoholism'. Jan, a Pastor in the Deeper Life Christian Centre of Louisville, Kentucky, was invited to....
The author of this bit of putative reportage claims to have ascertained not just what a Deeper Life pastor says about the curative powers of her faith, but what she actually has achieved.

The Giants scored a come-from-behind 5-4 victory over the Dodgers yesterday at Candlestick Park.

All the expertise of Hollywood could not win a gold medal for the production of yesterday's Los Angeles opening ceremony. The LA producers and organisers tried to beat the superb opening of the Moscow Olympics four years ago-and failed.

Walter Mondale scored another points victory over President Reagan in their second televised debate.... Mr. Mondale's victory was not a knockout but...

These passages appear to be remarkably similar in character. Each seems to be an account of the outcome of a contest. And each names a result directly, rather than naming a source or authority. Each accordingly could be characterized as a piece of pseudo-narrative, in which the grammar of narration is used as a vehicle for delivering a personal verdict.

But this characterization is suitable only for the second and third passages. In the first passage we have a representative bit of sports journalism, in which the narrator reports the official judgment on the outcome of a contest, without directly saying so. Rauditors know from experience that the reporter is not just giving his own opinion about who won; he is passing along the designated scorekeeper's verdict.

This kind of journalism is mundane. Journalists routinely make direct statements about who won a tennis match, an election, a lawsuit or some other contest. In doing so they normally are passing along the verdict of some authority: the official scorekeeper, the returning officer, the presiding judge, and so on. They are not giving a personal opinion about which contestant gave the best performance. To this end there must be an official judge, whose 
verdict is ascertainable.

But that condition did not apply to the Moscow and Los Angeles Olympic Games. Neither did it apply to the dialogue between Mr. Mondale and Mr. Reagan. (The two candidates did not engage in a debate, as there was no resolution before them. No person was designated officially to say which speaker 'won' the dialogue). Thus, the journalists who delivered ostensible accounts of the outcomes of contests, as quoted above, were only pretending to do reportage. They used a conventional narrative mode, and the context of newsgiving, as a vehicle for gratuitous evaluation. ${ }^{5}$

Sincerity. Narrative statements convey suggestions about subjective as well as objective events. They convey suggestions about the mental states of senders and receivers. As regards receivers, they convey the Salience Nudge ('this concerns you') and, occasionally, a Common Knowledge Nudge (to be discussed shortly). As for sender's mental state, a single narrative statement conveys plural suggestions. By voicing an " $X$ happened" statement, speaker invites several inferences concerning what she believes. Those invited inferences are that she believes that what she has said is (i) true, (ii) intelligible to average respondents, (iii) truth-valuable, (iv) ascertainable, and (v) noteworthy. (See Levinson, 1983, p. 105, citing Grice and Searle).

\section{Particular Suggestions}

Virtually all journalistic narratives prompt rauditors to credit their terms with intelligibility, feasibility (or truth-value), ascertainability, salience (noteworthiness, relevance) and truth, as well as to credit their authors with belief in the cogency of those suggestions. And there can be more nudges. Coinciding with the six 'standard' suggestions conveyed by journalistic nar- ratives are additional ones. These vary according to sub-type of narrative utterance. They pertain to event locations, agent numbers, common knowledge, sequences, order of importance and causation of events, as well as to the practicability of deeds.

Location. Narrative statements vary in completeness. Some specify what was done, in what circumstances, by whom, when, where and even whence. Others omit mention of one descriptive dimension or several. But some omissions can be suggestive.

If a reporter omits to specify where an event has occurred, her rauditors do not always feel ignorant of its spatial nexus. We often take the absence of locational remarks as a locational clue: a signal that the event happened here-that is, in a locality shared by narrator and rauditor(s) or in narrator's vicinity. According to a tacit conversational convention, location needs to be stated explicitly only when an event takes place somewhere other than here.

A corresponding convention reigns in the Press. Newspaper articles recounting out-of-town events start with datelines specifying the reporter's communication base. Articles about local events carry no datelines. The omission of datelines signals that the scene of reported action is local.

Number. Some narratives allude to quantities of agents, events, or objects. And many quantitative allusions go beyond their immediate terms and logico-semantic implications.

"Pete pushed Pam," for example, invites the inference that Pete alone pushed Pam. And "Nan had seven children" suggests that Nan had only seven children, although the statement does not preclude a larger number. This illustrates a general pattern whereby voicing a numerical specification suggests an outside limit. (See Levinson, 1983, pp. 147, 106.) Thus, "Betty was belted eight times" suggests that Betty was not struck more than eight times.

Also noteworthy are suggestions con- 
veyed by narratives alluding negatively or positively to numerical sets. "Not all of the children went to the movies"' suggests that some of the children went. "Some of the children went" suggests that some did not go. And "Many of the children complained" suggests that some did not complain. (See Leech, 1983, p. 9; Blakemore, 1987, p. 3.)

By the same token, "Dave just got a dismissal notice" suggests that Dave's experience sets him apart from workmates. If I say "Dave just got a dismissal notice" when the same thing happened to Dave's mates and I know it, I would not be lying or reasoning badly, but I would be violating a conversational maxim (see Grice, 1975), or committing what Strawson calls (1952, p. 1789) "a linguistic outrage."'6

Common Knowledge. Narrative statements convey suggestions not only about what has happened, but also about what is currently known. They do this most succinctly by means of speaker's choice of articles, definite (the) and indefinite (a, an).

If I say "Phyllis filled the tank" I invite the inference that the cited tank's identity is already known to my rauditors (perhaps by means of previous statements). A declaration that "Paul Newman, the film actor, went berserk yesterday" suggests that Mr. Newman already is a well-known figure. The contrary suggestion would be made in a sentence saying "Paul Oldboy, a film actor, went berserk."

Suggestions emanating from speaker's choice of articles are not confined to suggestions about common knowledge. "Belle went into a house yesterday" invites the inference (see Harnish, 1977) that the house entered was not Belle's. (Substitution of 'the' for ' $a$ ' would not impart the contrary suggestion; use of the possessive pronoun 'her' would do so). Moreover, "Wilf took a woman to dinner last night" is substantively non-committal or non-informative about the status of Wilf's dining companion; but the conversational thrust of such a sentence-the invited inference-is that the woman was not Wilf's wife, close relative, or close platonic friend. (See Leech, 1983, citing Clark \& Clark.)

Chronology. According to Clark \& Clark (1977, pp. 78, 123), speakers generally adhere to an "order of mention contract" whereby "events are normally described in the order in which they occur." 'The boy jumped over the fence and patted the dog,' for example, indicates that the boy jumped over the fence before and not after he patted the dog.

Approaching the same subject from the standpoint of rauditors, Harnish (1977, p. 359 , drawing upon Strawson) observes that we place different interpretations on compound sentences which differ only in order of items. We draw contrasting sequential inferences, for example, from sentences saying "They got married and had a baby" and "They had a baby and got married." We do so, says Harnish, because we credit speakers with fidelity to a conversational maxim prescribing "Be representational; in so far as possible, make your sayings 'mirror' the world."'

Levinson (1983) makes a similar point. "The lone ranger jumped on his horse and rode into the sunset," he says, conveys the suggestion that those two deeds occurred in the order mentioned. As rauditors we harbor the "expectation" that "events are recounted in the order in which they happened" (pp. 98, 108).

On this showing (see also Blakemore, 1987, pp. 22, 36), speakers who include several past events in a single narrative text do not need to use direct statements in order to convey suggestions about event sequences. They convey chronological suggestions anyway.

Gradation. The foregoing version of suggestions conveyed by narrative sequencing needs to be amended heavily. It is inconsistent with suggestions conveyed by many narrative texts encountered in daily life. It is inconsistent particularly with the nature of narrations appearing in the news 
media. Here the recurring suggestion is that order of mention betokens order of importance.

This suggestion is implicit in discourses billed as "newscasts." The standard newscast is short temporally and miscellaneous topically: one sentence or a few sentences about one event, then a sentence or two about an altogether different event, and so on--with minimal differentiating signals. And conveyed in the newscast is the suggestion that the first item out-weighs the next in importance, and so on. This suggestion may be reinforced by explicit reference to "our top story of the hour."

A similar suggestion is conveyed in Press stories. Print journalists customarily begin articles with what they take to be the most important disclosure: a synoptic statement, the most important passage in a speech, the most important of several decisions reached at a legislative sitting, the latest episode in a 'continuing' story, the most novel aspect of an event, and so on. Criteria for deciding what is more and less important are elusive and various. But the idea of relating order of narration to order of importance supersedes concern with chronology. Journalists are taught to write in this manner, so that their stories can be cut, paragraph by paragraph, from the bottom up. ${ }^{7}$

This pattern of suggestion contravenes the notion that order of mention signifies order of occurrence.

Whether these countervailing patterns of suggestion create confusion among rauditors depends on how much they depend on context. Perhaps the order of items mentioned in ordinary discourse conveys one suggestion, while the order of items mentioned in news media discourse conveys another.

Derivation. Some narratives convey suggestions not only about what happened but also about why or how. Narratives of this sort encourage causal inferences without voicing causal claims.

Narrative angle as explanatory nudge.
One source of causal suggestion is speaker's choice of narrative angle. An example:

Giants Fall Apart Against Reds.

S.F. Blows a 5-0 Lead-Loses 8-6.

Invited by this headline is the inference that in determining the outcome of a baseball game the Giants were active while the Reds were passive agents. ${ }^{8}$

In a similar way, "John kicked the dog", invites the inference that John's deed was intentional. This case illustrates a larger pattern (as is suggested by Harnish, 1977, p. 384) whereby sentences which can be construed as references to volitional behavior 'shall' be so construed unless the speaker explicitly disclaims such an interpretation. That convention can put quite a strain on rauditors from time to time, as journalists liven their prose with such images as these:

Cow Kills Motor Cyclist.

Cricket ... attacked the wrong end of the Packer problem. Wounded, it went for the players ... More wisely, it should have gone for the play.

Judge Nicholson and his daughter ... were the latest victims of a small stretch of highway that has killed six people in less than 12 months.

Australia yesterday denied rumours that it was inviting immigrants from Cuba...

Co-responsibility as collaboration. If more than one agent is credited with a deed, the invited inference is that the agents acted in concert. This sort of suggestion has been noticed by Harnish (1977, p. 358), who instances the statement "Sam and Joe moved the table." According to standard logicosemantic rules, that statement is compatible equally with collaboration (each man picked up an end) or with successive input (each man alone moved the table part of the way). But according to conventional usage only the former interpretation is 'supported'. And conversely, a statement imputing action to one agent ("Bill did $D$ ') invites the inference (see Levinson, 1983, p. 147) that the agent was not joined by 
others.

Characterization as explanatory nudge. If I say "The sick soldier stumbled" I invite an inference not only about what happened but also about why it happened. I invite the inference that the soldier stumbled because he was sick. Similarly, "Six swains surrounded the dazzling debutante" suggests-but does not entail logicosemantically - that the deb's dazzle had much to do causally with her being surrounded. ${ }^{9}$

Succession as explanatory nudge. Another way of inviting causal inferences without making direct causal claims (as was mentioned in the discussion of Geis \& Zwicky) is to name a sequence of events. Chronological statements - " $A$ happened, then $B$ ", or " $B$ happened after $A$ "represent acts of selection. After all, every event's antecedents are multitudinous. By selecting one antecedent for mention, speakers invite us to impute special importance. And when we cast about (halfconsciously) for a rationale, we are apt to hit upon the idea of causal force. An illustrative passage:

The U.S. bombed Libya in the wee small hours of Tuesday. By the end of the day the Stock Exchange had lost almost $\$ 10$ billion in value.

Invited here, without being affirmed or implied formally, is the inference that the firstnamed event caused the second. (Also invited is the erroneous inference that the events named actually took place. ${ }^{10}$ )

This pattern of suggestion can be made in personal (autobiographical, biographical) as well as impersonal terms. "After I took the pills, my headache went away, " for example; and "After Gail tried Tamps, she met Glenn, and then...."

These statements, to repeat, do not contain explicit causal claims. Their authors thus cannot be accused of committing the False Cause fallacy (post hoc, ergo propter $h o c)$. The authors' words, however, do tempt us to 'see' a causal claim and to draw a causal inference. The latter comes about by asking oneself why a speaker picked that antecedent for mention, and answering in terms which credit speakers with the desire and ability to provide useful knowledge. (See Blakemore, 1987, Ch. 4.)

Much is at stake here. Advertisers know this well. They often devise messages in which a putative witness testifies that after using a named product (s)he experienced benefits. The invited inference is that using the named product (rather than using any rival product, or doing nothing) caused the gains.

In politics, similarly, much is at stake in explanatory prose-and thus in tacitly as well as in explicitly explanatory prose. Our feelings about events and agents, our positive and negative appraisals, vary according to our hunches about determinants. If I believe Bloggs was fired because he slept on the job, rather than because he discovered that his boss was embezzling company funds, I feel his dismissal was justified. To that event I feel disposed favorably towards Blogg's boss, and might give him my vote if the occasion should arise. And yet it could be the case that Bloggs was fired after he slept on the job and after he discovered the embezzling and after many other events. A narrator can influence one's hunch about causation, and then about propriety, simply by choosing among antecendents. Whatever antecedent he names is the one we are apt to construe as the main causal antecedent.

This was richly illustrated in the course of media coverage of a political upheaval back in October 1985 in the State of Queensland, Australia. A Cabinet Minister in a National Party-Liberal Party coalition government was dismissed from office, and this set in motion a string of events which for the coalition partners was momentous. On subsequent days, journalists covering the unfolding "Coalition Crisis" harked back to the dismissal. They produced numerous sentences starting with " $\mathrm{Mr}$. White was sacked after..."' In numerical preponderance, preferred terms for com- 
pleting the sentence were about as follows: "... he crossed the floor of Parliament with seven Liberal backbenchers to vote in favour of opening debate on establishing a public accounts committee."

Rarely mentioned was another antecedent: that Mr. White's dismissal came after he voted to discard the agenda which he and his Cabinet colleagues had decided three days earlier to adopt. This omission made it difficult for Queensland voters to identify the basis for the claim that Mr. White had committed a breach of the Westminster principle of Cabinet solidarity.

Practicability. Ostensible accounts of past events convey suggestions not only about what took place in the past but also about what can take place in the present and the future. If I say "I tried those new Pumas yesterday and cut a second off my half-mile time," for example, I invite the inferences that the new shoes caused my improved time and that other runners CAN make a similar change and then WOULD experience a similar outcome. My words make no such claim explicitly. But unless I give an overt disclaimer, stipulating that only my special traits enabled me to make that improvement, the causal claim is 'heard.' My rauditors are encouraged to believe that I have transmitted information which they can use.

Advertisers play upon this susceptibility. They often present ostensible cases in which some individual says he tried a product ("new improved Gleamo") and then underwent a pleasurable experience ("brighter teeth," "new romance"). Direct causal claims (" $A$ caused $B$ ") are avoided. So are causal promises (that for other people, doing the equivalent of $A$ would produce a gain of $B$ ). Advertisers rely instead on our willingness to make the jump from the practicability of emulation ("I can use Gleamo too") to the probability of result-repetition ("So I'd probably make similar gains").

Here is the text of an advertisement which is cast in narrative terms:

Wednesday: He hardly even glanced at me.

Thursday: Invested...in a packet of
Harmony Hair Colour. Friday: Things look rosier somehow.

Adjacent graphics show a female who first looks scruffy-haired and dejected, and then looks bright-coiffed and happy while clinging to a handsome man. This text (see Williamson, 1978) makes no causal claim, either immediately ("Harmony Hair Colour caused her change") or generally and prospectively ("using H.H.C. would produce a similar change for you"). Yet the putative narration invites us to infer that by using 'Harmony' women generally would acquire better-looking hair, which in turn would give them happier lives. It also invites us to take for granted the practicability of such a trial.

\section{Summary}

In the foregoing pages we have considered suggestions, or invited inferences, which communicators convey by means of putatively reportorial verbiage. We have concentrated on suggestions which are conveyed 'indirectly' rather than being entailed logically. Attention was devoted to six kinds of suggestions which seem to be conveyed by the generality of journalistic narratives, and to seven which get conveyed by particular varieties of narratives. Results of the canvass can be condensed with the aid of some easily decipherable symbols. Here is a taxonomy.

\section{NARRATIVE CUE SUGGESTIONS}

"A happened" Veracity: $A$ did indeed happen. Intelligibility: Terms used are comprehensible

Feasibility: Event $A$ could have occurred.

Ascertainability: Occurrence of $A$ could have been learned by narrator.

Salience: $A$ is noteworthy (more so than non- $A$ )

Sincerity: Speaker believes all of foregoing. 


"A happened"
(vs. " $A$
happened in
place $P$ ')
"A happened
$n$ times"
"Di did $A "$
"A happened
to Di"
"Not all $B$ 's
did $A "$
"Some $B$ 's
did $A "$
"Many $B$ 's
did $A "$
"Di did the $A "$
"The agent
did $A "$
"An $F$ did $A "$
"A \& $B \& C$
happened"

Location: A happened here

Number: $A$ did not happen more than $n$ times.

Only Di did $A$.

$A$ happened only to Di.

Some B's did $A$.

Some B's did not do A

Some $B$ 's (a minority?) did not do $A$.

Common Knowledge: Identity of deed $A$ is known.

Identity of cited agent is known.

Identity of agent is not known.

Chronology: $A$ happened, then $B$, then $C$.

Gradation: An importance, $A$ surpasses $B$ and $C$.

"Di did $A$ ", Causation: Di was primary causal agent of $A$.

"Di \& El did $A$ " Di and El collaborated.

" $B$ happened after $A$ "

"The $b$-ish $F$ did $A$ "

$A$ contributed causally to $B$.

" $F \operatorname{did} A$ and got $Y$ ",

$F$ 's $b$-ishness contributed causally to $F$ 's $A$-ing.

Practicability: Other agents can do equivalent of $A$ and would then incur equivalent of $Y$.

That collection is not complete. It does not, for example, pave the way for appreciating every nuance in this sentence:

Earlier this year, [Senator George Georges] went on record to express his disappointment and disenchantment with the sudden lurch to the Right of his party....11

Nevertheless, our collection deals rather comprehensively with patterns of suggestion that are conveyed by the use in realworld contexts of sentences exemplifying journalistic narration.
I have concentrated, to repeat, on identifying patterns of suggestion or invited inference. Little attention has been paid to processes which bring about these patterns of suggestion, or to considerations affecting the prudential acceptability of invited inferences.

Some of the most promising explanatory material is to be found in the muchexplicated work of Paul Grice on conversational implicature. Grice has concentrated, however, on inferences which can be derived plausibly from messages if one credits senders with fidelity to an overarching Principle of Co-operation and to a set of instrumental linguistic Maxims. Rauditors often cannot know whether messages come from senders who are imbued with the will and endowed with the means to be co-operative. Rauditors cannot readily decide, then, which implicatures qua invited inferences deserve to be accepted. They might welcome the formulation of suitable, cost-effective decision rules. Such rules would help them to decide which of the many invited inferences they encounter are warranted prudentially.

\section{Notes}

1 The nature of what the narrator is endowing with salience can depend not only on the terms of a narrative statement, but also on where emphasis (if any) is placed. This has been nicely illustrated by Strawson (via Kempson, 1975) who dwells on the contrast in suggestions conveyed by variations in placement of emphasis within a single three-word sentence: (1) "John seduced Mary"; (2) "John SEDUCED Mary"; (3) "John seduced MARY"; and (4) "JOHN seduced Mary".

Strawson says these sentences differ in presuppositions. That surely is a misnomer (and in any event, Strawson does not name the contrasting presuppositions). The sentences differ in sug- 
gestive thrust-in what they invite hearers to infer about what is important concerning what took place. They differ, that is to say, in what questions they answer, namely (1) What's new?; (2) What is it that John did to Mary? (We already know he did something); (3) Who did John seduce? (We know he seduced somebody); (4) Who seduced Mary? (We know that somebody did).

Similar nudges can be imparted by cleft constructions. Thus, "It was Susan who bought the chicken" invites the inference that special importance in connection with a chicken acquisition attaches to the identity of the purchaser. And "It wasn't Alex who solved the problem" suggests that with regard to a problem-solving event, special importance attaches to the identity of the solver. (See Blakemore, 1983, p. 99; and Soames, 1976.)

2 This case is tidier (dangerously so?) than what Clark \& Clark provide. They make the point $(1977$, p. 130) that "Ann Boleyn was beheaded in 1536" conveys more information, or putative information, than does saying Boleyn "was e $x$ ecuted", "was killed" or "died." But the latter verb points in several directions. It suggests that Boleyn died of natural causes, or that speaker does not know how she died, or that speaker deems the cause of Boleyn's death extraneous to his present account.

3 In the words of Kress \& Hodge (1979), "descriptions involve language, and presenting anything in or through language involves selection." A newspaper reporter "may witness an event and then be faced with the choice of calling it a demonstration (or a demo), a riot, a street battle, war on the streets, a confrontation, or [sic] so on." These remarks confound the problem of choosing among events (or aspects of events) with the problem of choosing among descriptive terms. Mainstream journalists generally minimize the latter problem by concentrating on what informants say about events (" a demonstration occurred"; "it was a riot").

4 Some linguists teach that " $\mathrm{X}$ happened" presupposes feasibility (that ' $\mathrm{X}$ ' is the name of something that could have happened). But words do not have minds; they cannot suppose. Speakers do have minds; they do make suppositions; but we cannot readily infer what they suppose from what they say.

5 This sentence invites the inference that the writer is responsible for the context as well as the text of his story. Not so. When a putative reporter files nonreportorial copy, his editor is under no obligation to publish it in the guise of news.

6 Strawson's example and discussion bear repeating, as they sharpen the distinction between logico-syntactic implication and verbal suggestion:

$$
\begin{aligned}
& \text {...if someone, with a solemn face, says } \\
& \text { 'There is not a single foreign book in this } \\
& \text { room,' and then later reveals that there } \\
& \text { are no books in the room al all, we have } \\
& \text { the sense, not of having been lied to, but } \\
& \text { of having been made the victim of a sort } \\
& \text { of linguistic outrage. Of course he did } \\
& \text { not say there were any books in the } \\
& \text { room, so he has not said anything false. } \\
& \text { Yet what he said gave us the right to } \\
& \text { assume that there were, so he has mis- } \\
& \text { led us. }
\end{aligned}
$$

7 The pattern of suggestion that occurs in Press stories also is conveyed by whole pages. Just as first place in a story 'means' topical primacy, so does top place for a story (and biggest headline). Graphic cues of this kind, and many more kinds, belong to the rich topic of visual rhetoric.

8 This suggestion may be a product of nothing more subtle than home-town primacy, in which the local team regularly gets portrayed as active agent in contests with other teams. Perhaps the Reds' 
home-town paper conveyed an alternative suggestion, in a headline saying "Reds Rebound. Turn 0-5 Deficit into 8-6 Win".

9 Clark \& Clark (1977, Ch. 2) make the point that placement as well as choice of adjectives shapes explanatory thrust. They illustrate by means of two sentences:

\footnotetext{
"The young troops that defeated Napoleon's army were fresh."

"The fresh troops that defeated

Napoleon's army were young."
}

The sentences convey contrasting hints about determinants of Napoleon's defeat. But the Clarks do not specify the contrast and I feel unable to do so. Meanwhile, Schmidt \& Kess (1985) make a similar point, citing the contrasting nudges imparted by the phrases "modern popular music" and "popular modern music."

10 The Stock Exchange did not lose anything. Shares traded on the Exchange underwent a net decline in prices. As for the bombing, it was done not by "the U.S." but by some U.S. Air Force pilots who were acting on orders. Those bombs did not hit "Libya"; they hit sites in Libya. According to some journalists' accounts at the time, those sites were "terrorist bases."

(My use of invited inference in the foregoing sentence is noteworthy. Without voicing a statement about veracity I invite the inference that those "some journalists" were correct.

This case deserves elaboration, although it takes us outside the realm of formally narrative discourse. Mainstream journalists often voice claims about what is believed, is understood, or is expected to be the case. They name no believers. Their words still invite the inferences that what alleggedly is believed (i) is generally believed and (ii) is true.)
11 Among suggestions conveyed by this bit of putative reportage (by Marion Smith in The Sunday Mail of Brisbane, Australia, 20 April, 1986-and the senator's name really WAS George Georges):

-Use of verbal phrase "went on record" instead of simpler and more common "said" suggests the senator delivered his complaint on a special occasion, such as press release dealing only with this matter, or prepared speech.

-Use of possessive adjective "his" takes on significance in view of its superfluity. Writer could easily have said simply "...to express disappointment and...." By inserting "his" the writer invites the inference that Senator Georges really WAS disappointed, and did not just SAY he was disappointed. Use of "his" thus signals authorial claim to mind-reading powers.

-Use of capital letter signals figurative construction of "lurch to the $R$ ight" but does not enable readers to translate author's figure of speech.

- "...disenchantment with the sudden lurch to the Right of his party..." is noteworthy for what it leaves out: language stipulating that writer is only recording source's version of what has happened. By omitting to say " "...disenchantment with WHAT HE CHARACTERIZED AS a sudden lurch...", writer claims (in effect; sneakily) that the alleged lurch really did take place.

-Similarly, by leaving out that stipulation, writer endorses notion that expression "sudden lurch to the Right of his party" is immediately intelligible to average readers. By way of contrast, if I say "the senator voiced disappointment at WHAT HE CALLED a sudden lurch to the Right of his party, " I take no position on whether lurch took place and whether image of Right-ward lurch by "party" is coherent.

-By alluding to "sudden lurch to the 
Right," writer joins senator in voicing two-fold accusation: that deplorable Rightward shift has occurred; and that same has been unduly abrupt.

\section{References}

Bach, Kent \& Robert H. Harnish. 1979. Linguistic Communication and Speech Acts. Boston: M.I.T. Press.

Beardsley, Monroe. 1950. Practical Logic. New York: Prentice-Hall.

Blakemore, Diane. 1987. Semantic Constraints on Relevance. Oxford: Basil Blackwell.

Clark, Herbert H., \& Eve V. Clark. 1977. Psychology and Language. An introduction to psycholinguistics. N.Y.: Harcourt Brace Jovanovich.

Coleman, Linda. 1982. A Linguistic Analysis of Television Commercials. Doctoral dissertation, Linguistics Dept., University of California, Berkeley campus.

Fogelin, Robert. 1978. Understanding Arguments. An introduction to informal logic. N.Y.: Harcourt Brace Jovanovich.

Geis, Michael. 1982. The Language of Television Advertising. N.Y.: Academic Press.

Geis, Michael, \& Arnold Zwicky. 1971. "On invited inference." Linguistic Inquiry, vol. 11 no. 4, pp. 473-78.

Gordon, David, \& Gordon Lakoff. 1971. "Conversational postulates," in Papers from the 7th Regional Meeting, Chicago Linguistics Society, pp. 63-84.

Grice, Paul J. 1973. "Logic and conversation," in The Logic of Grammar, ed. D. Davidson and G. Harman. Encino, CA: Dickinson.

Harnish, Robert. 1977. "Logical form and implicature," in An Integrated Theory of Linguistic Ability, "by" Thomas G.
Bever, Jerrold J. Katz and D. Terrence Langendoen (who are not billed as editors). N.Y.: Thomas Y. Crowell, pp. 313-92.

Holdcroft, David. 1978. Words and Deeds. London: Oxford University Press.

Kempson, Ruth. 1975. Presupposition and the Delimitations of Semantics. Cambridge: Cambridge University Press.

Kress, Gunther, and Robert Hodge. Language as Ideology. London: Routledge \& Kegan Paul.

Lakoff, Robin. 1977. "What you can do with words: politeness, pragmatics and performatives." Berkeley Studies in Syntax and Semantics, vol. 16 no. 1.

Leech, Geoffrey N. 1974. Semantics. Harmondsworth, UK: Penguin Pelican. 1980. Explorations in Semantics and Pragmatics. Amsterdam: John Benjamins B.V.

1983. Principles of Pragmatics. London: Longman.

Levinson, Stephen C. 1983. Pragmatics. Cambridge: Cambridge University Press.

May, John D. 1980. "Journalistic lateralism," Australian Journalism Review, vol. 3 no. 2, pp. 11-16.

Nowell-Smith, P.H. 1954. Ethics. Harmondsworth, U.K.: Penguin.

Pateman, Trevor. 1983. "How is understanding an advertisement possible," in Language, Image, Media, ed. Howard Davis and Paul Walton. Oxford: Basil Blackwell.

Rubenstein, Herbert. 1973 " 'Language and probability," in Communication, Language and Meaning, ed. George Miller. N.Y.: Basic Books, Ch. 17.

Schmidt, Rosemarie, and Joseph F. Kess 1985. "Persuasive language in the televi- 
sion medium. Contrasting advertising and televangelism." Journal of Pragmatics, vol. 9, 287-308.

Soames, Scott 1976. "A projection problem for speaker presuppositions," Linguistic Inquiry, vol. 10 no. 4, pp. 623-66.

Stalnaker, Robert. 1974. "Pragmatic presuppositions," in Semantics and Philosophy, ed. Milton K. Munitz \& Peter K. Unger. New York: New York University Press, pp. 197-213.

1975. "Presuppositions" in Contemporary Research in Philosophical Logic and Linguistics, ed. D.J. Hocking, W. Harper and B. Fried. Dordrech,
Holland: D. Reidel, pp. 31-41.

Strawson, P.F. 1952. Introduction to Logical Theory. London: Methuen.

Wilensky, Robert. 1989. "Primal content and actual content: an antidote to literal meaning." in Journal of Politics, vol. 13, no.2, pp. 163-86.

Williamson, Judith. 1978. Decoding Advertisements. Ideology and Meaning in Advertising. London: Marion Boyars.

John D. May, 91 Musgrave Road, Indooroopilly, Queensland 4068, Australia 